\title{
Factores de (In)Sucesso no Ensino Básico: Perspectivas de Encarregados de Educação
}

\section{Causes of School Success/ Failure in Basic Education: Perspectives of Parents}

\author{
Teresa Santos, Maria Alves \\ Universidade do Minho
}

\begin{abstract}
Resumo
O tema da relação entre avaliação e sucesso escolar é muito debatido pelos decisores políticos, professores, alunos e encarregados de educação mas, frequentemente, é reduzido à natureza sumativa ou certificativa da avaliação. Apresentamos alguns resultados de um estudo, realizado num agrupamento de escolas, localizado na zona Norte, cujo principal objetivo é conhecer a perspetiva dos Encarregados de Educação (EE) sobre o sucesso escolar e, consequentemente, o sentido que atribuem ao currículo e à avaliação das aprendizagens.

Os resultados revelaram que não há grande divergência de opiniões entre os EE dos alunos com mais e com menos sucesso escolar. Salientam que a forma como os professores avaliam e acompanham os seus educandos pode aumentar a motivação e o estímulo, reconhecem como fatores que podem interferir no sucesso dos seus educandos a articulação escola família, as tecnologías da informação e da comunicação, as redes sociais e o currículo.

Palavra-Chave: Sucesso Escolar, Avaliação das Aprendizagens, Ensino Básico, Encarregados de Educação.
\end{abstract}

\begin{abstract}
The relationship between evaluation and school success is much debated by policy makers, teachers, students and parents, but it is often reduced to the summative or certifyed nature of evaluation. We present some results of a study carried out in a group of schools, located in the North area, whose main objective is to know the perspective of parents on school success and, consequently, the meaning they attribute to the curriculum and the evaluation of learning.

Results highlited that there is not a great divergence of opinions among parents whose children are well succeded and those having less school success. They emphasize that the way how teachers evaluate and accompany their learners increase motivation and stimulation and recognize that the articulation family-school, information and communication technologies, social networks and curriculum, are factors that can interfere in the success of their children.

Keywords: School Success, Assessment of Learning, Basic Education, Parents.
\end{abstract}

\section{Introdução}

O tema da relação entre avaliação e sucesso escolar é muito debatido pelos decisores políticos, professores, alunos e encarregados de educação, mas frequentemente, reduzido à natureza sumativa ou certificativa da avaliação. A revisão da literatura salienta que a avaliação tem como finalidade a promoção do sucesso educativo, de modo que se constitui num mecanismo para aferir a qualidade das aprendizagens, a incluir professores, projetos, currículos, programas, materiais, ensino ou políticas, com vista a uma melhoria sustentada de todos os dispositivos, nomeadamente, os relativos às aprendizagens dos alunos.

Neste contexto, Simão (2008, p.125) afirma que a avaliação das aprendizagens "é uma componente fundamental da educação escolar e dos processos escolares de ensino e de aprendizagem e que os esforços para melhorar a educação exigem, necessariamente, a melhoria das práticas de avaliação". Acrescenta Alves (2004) que o ato de avaliar deve "permitir observar a evolução global dos alunos", sendo necessário avaliar "não somente as prestações cognitivas, mas igualmente o investimento, o progresso e o domínio afectivo" (Alves, 2004, p. 73).

Porém, as práticas de avaliação das aprendizagens cumprem diferentes funções e são aplicadas diferentes modalidades. Para Alves e Sá (2014, p.531) "as modalidades e funções de avaliação mais tradicionais, [...] tem vindo a ser ampliadas como formas de avaliação formativa, com a função de acompanhar todo o processo de ensino aprendizagem e contribuir para a melhoria contínua das aprendizagens".

Neste entendimento, a avaliação formativa é um instrumento de regulação, permite ao aluno a assunção de um maior controlo e responsabilidade do seu próprio processo de aprendizagem, assim como um domínio progressivo das matérias para a execução e realização das tarefas. Para tal, o erro debe deixar de ser visto como uma lacuna, passando a ser aceite como um indicador do percurso de aprendizagem, em que o aluno está no centro.

Neste contexto, realçamos a importância do feedback, pois "regula e controla os processos de aprendizagem, assim como serve para melhorar a motivação e autoestima dos alunos" (Fernandes, 2006, p. 31). 
A relevância que todos os autores citados atribuem ao aluno, colocando-o numa posição de protagonista do processo de ensino aprendizagem, só poderá existir na prática se ao aluno forem concedidos os instrumentos necessários para que ele seja capaz de ser autónomo e de estar motivado para a aprendizagem.

Outro dispositivo gerador de sucesso e insucesso é o currículo, ainda que sejam várias as interpretações e teorizações acerca do conceito de currículo. Para Roldão (2013, p. 131) "em sentido lato corresponde ao corpo de aprendizagens (conhecimentos de vários níveis e tipos, valores, técnicas, outros) de que a sociedade considera que precisa para sobreviver e de que cada um do seus membros precisa de se apropriar para nela se integrar de forma satisfatória", não sendo sempre as mesmas disciplinas, mas "o conjunto de aprendizagens que, por se considerarem socialmente necessárias num dado tempo e contexto, cabe à escola garantir e organizar”. (Roldão, 1999, p.24))

Para Alves (2001, p. 161) “(...) trata-se de um território com diversas texturas e interações entre o pensamento dos professores, dos alunos (as suas teorias, crenças e

conhecimento) e da cultura (os conteúdos, as tarefas, as tradições académicas...)."

$\mathrm{Na}$ perspetiva de Roldão (1999) os programas constituem-se apenas em instrumentos do currículo e, por isso, são contextuais, reconvertíveis e mutáveis. Mas os "programas" para um certo conjunto de aprendizagens podem ser diversos e organizados de várias maneiras" (Roldão, 1999, p.35).

Para Pacheco (2010), o currículo está ligado à escola e à sala de aula, mas existe uma discrepância, entre o currículo que é suposto ser ensinado (currículo prescrito) e o que efetivamente é desenvolvido por cada professor ( currículo real) porque, a partir dos programas, os professores, tendo em conta as características e necessidades dos seus alunos, irão implementar a sua «interpretação» a partir do que está previsto para determinado ano/ciclo de estudos e realizar a avaliação em consequência das aprendizagens adquiridas.

Muitos investigadores (Crahay, 1996; Formosinho, 1991 e 2012; Sil, 2004; Mendonça, 2009; Azevedo, 2014; Santos \& Alves, 2016) ao abordar a problemática da avaliação e do (in)sucesso escolar, incidem particularmente nas suas causas, nos seus efeitos e na forma como se pode combater o insucesso ou promover o sucesso. Geralmente, o uso da expressão "sucesso escolar" utiliza-se naquelas situações em que não há reprovação de alunos ou retenções. As situações de insucesso escolar são provocadas por uma multiplicidade de causas e não apenas por um fator, podendo ser o corolário de muitos problemas que têm por denominador comum a não satisfação das necessidades reais da criança (Sil, 2004).

O sucesso escolar dos alunosreúne uma grande complexidade e deve ser analisado sob um ponto de vista multidimensional assente nas seguintes variáveis: (1) individual, do aluno e da sua família; (2) dos professores, pedagógico/didático; (3) institucional, da escola, da sua orientação e do seu funcionamento; e (4) da comunidade envolvente, com destaque para as características das famílias que predominam no contexto local (Azevedo,
2014). Assim, falar do sucesso ou do insucesso escolar é por em causa não apenas os alunos, mas também os professores, os pais, o ambiente que rodeia a criança, a instituição em si, os responsáveis pela educação nacional e toda a comunidade.

Com o aumento da escolaridade obrigatória até aos 18 anos, a escola deveria ser cada vez mais de todos e para todos, visando o sucesso escolar de todos, porém nem todos obtem o referido sucesso. Ele depende também da capacidade, do esforço despendido, do desejo para aprender, das expetativas que os estudantes e as suas famílias tem sobre os resultados escolares.

Na perspetiva de Formosinho e Machado (2010), a reorganização da escola tem tido por referência a "gramática" da turma-classe, ou seja, classes, "os professores atuam sempre a título individual, induzindo uma pedagogia centrada essencialmente na sala de aula; horários escolares rigidamente estabelecidos que põem em prática um controlo social do tempo escolar; saberes organizados em disciplinas escolares" (Formosinho \& Machado, 2012, p.40). Os autores contrapõem com três modelos de organização do ensino: organização do processo de ensino por turmas independentes; organização do processo de ensino por turmas contíguas; organização do processo de ensino por equipas docentes.

$\mathrm{O}$ conceito de melhoria ligou-se ao de eficácia, surgindo o movimento da melhoria da eficácia que aponta, exatamente, o "efeito da escola" como decisivo para o sucesso.

A escola tem de refletir para melhorar. Refletir sobre os resultados de aprendizagem, os processos internos ao nível da sala de aula, os processos internos ao nível de escola e, ainda, sobre as relações com a comunidade

Neste contexto, orientámos o estudo no sentido de identificarmos os factores que, na opinião dos EE afetam o percurso escolar dos seus educandos, o modo como o vivenciam e, consequentemente, o sentido que atribuem ao currículo e à avaliação das aprendizagens.

\section{Opções metodológicas}

\section{Descrição do estudo}

A metodologia utilizada foi de índole qualitativa, uma vez que privilegia os métodos descritivos e interpretativos, no sentido de procurar explicações em contexto real, ao descrever e interpretar a realidade em estudo, identificando as interpretações que dela fazem os atores convocados. A investigação qualitativa é baseada no método indutivo, em que o ambiente natural constitui a fonte direta dos dados, sendo o investigador $o$ instrumento-chave, pois "trata-se de investigar ideias, de descobrir significados nas ações individuais e nas intenções sociais, a partir da perspetiva dos atores intervenientes no processo" (Coutinho, 2011, p. 26). Neste contexto, quisemos conhecer como é que o mesmo problema pode ser visto, "interpretado e valorizado de formas diferentes", a partir de questões colocadas aos Encarregados de Educação "relacionadas com o que acontece na escola" (Santos Guerra 2003, p. 89-90), ou seja, pretendemos compreender como perspetivam a avaliação os EE dos alunos que obtêm mais e os que 
obtêm menos sucesso escolar. Neste sentido, formulamos os seguintes objetivos:

- perceber a forma como os EE entendem o estudo /sucesso e a importância que lhe atribuem; conhecer as suas percepções acerca da escola;

- analisar a maneira como acompanham os seus educandos.

\section{Caracterização do contexto e dos intervenientes no estudo}

O estudo foi realizado num Agrupamento de Escolas, localizado na zona norte de Portugal, cujo território educativo abrange três (3) estabelecimentos de educação pré-escolar, cinco (5) do $1^{\circ}$ Ciclo e um (1) do $2^{\circ}$ e $3^{\circ}$ Ciclos do Ensino Básico, a escola sede do agrupamento.

No ano letivo 2015-2016, a população escolar era constituída por 128 crianças (seis grupos) na educação pré-escolar; 282 alunos (15 turmas) no $1 .^{\circ}$ ciclo; 153 alunos (oito turmas) no $2 .^{\circ}$ ciclo; 276 alunos (13 turmas) no $3 .^{\circ}$ ciclo e 20 alunos nos cursos vocacionais (uma turma), num total de 859 . O ensino era assegurado por 89 docentes, dos quais, $99 \%$ pertencem aos quadros. A sua experiência profissional é significativa, pois $100 \%$ lecionam no agrupamento há 10 ou mais anos. O pessoal não docente é constituído por 38 profissionais que, na sua totalidade, têm 10 ou mais anos de serviço.

No estudo, participaram 8 encarregados de educação, cujos educandos frequentavam o oitavo e o nono anos de escolaridade, assim distribuídos: 4 cujos educandos não tiveram nenhuma retenção e 4 cujos educandos tiveram, pelo menos, uma retenção. Na tabela 1 , apresentamos a caracterização dos entrevistados, relativamente ao sexo, idade, habilitações académicas e profissão.

Tabela 1.

Perfil dos entrevistados Encarregados de Educação

\begin{tabular}{ccccl}
\hline Ee & Idade & Sexo & $\begin{array}{r}\text { Habilitação } \\
\text { académica }\end{array}$ & Profissão \\
\hline Ae1 & 49 & F & $12^{\circ}$ ano & Costureira \\
\hline Ae2 & 41 & M & $9^{\circ}$ ano & Segurança \\
\hline Ae3 & 63 & F & $4^{\circ}$ ano & Reformada \\
\hline Ae4 & 46 & F & Licenciatura & Professora \\
\hline Ae5 & 42 & F & $12^{\circ}$ ano & Escriturária \\
\hline Ae6 & 48 & M & $6^{\circ}$ ano & Camionista \\
\hline Ae7 & 54 & F & $6^{\circ}$ ano & $\begin{array}{l}\text { Empregada } \\
\text { Doméstica }\end{array}$ \\
\hline Ae8 & 45 & M & $6^{\circ}$ ano & Serralheiro \\
\hline
\end{tabular}

Em síntese, os entrevistados têm entre 41 e 63 anos de idade, situando-se a maioria na faixa etária dos 41-49 anos; $62,5 \%$ são do sexo feminino e $37,5 \%$ são do sexo masculino. Relativamente às habilitações académicas uma entrevistada possui o grau de licenciatura, duas possuem o $12^{\circ}$ ano de escolaridade, um possui o $9^{\circ}$ ano de escolaridade, três possuem o $6^{\circ}$ e uma entrevistada apenas possui o $4^{\circ}$ ano de escolaridade. Salientamos que quatro entrevistados possuem uma baixa escolaridade e exercem uma profissão que requer poucas habilitações e dois concluíram a formação já em idade adulta.

\section{Entrevistas}

A entrevista é um dos métodos apropriados para utilizar num estudo de caso sobre as instituições educativas, pois permite obter informações pertinentes, que não podem ser encontradas em registos ou fontes documentais. $O$ recurso à técnica das entrevistas semiestruturadas pareceu-nos ser o mais adequado para captar as perceções dos sujeitos da investigação sobre a temática em estudo, uma vez que possibilita "recolher dados descritivos na linguagem do próprio sujeito, permitindo ao investigador desenvolver intuitivamente uma ideia sobre a maneira como os sujeitos interpretam aspetos do mundo "(Bogdan \& Biklen, 1994, p. 134).

$\mathrm{Na}$ realização das entrevistas foi seguido o procedimento ético com todos os sujeitos que participaram neste estudo, pois consideramos que é fundamental e inseparável de todo o processo. Deste modo, foi inevitável termos em conta a proteção da identidade dos sujeitos, a informação sobre os objetivos do estudo e a garantia de confidencialidade das informações.

As entrevistas foram gravadas, transcritas e, posteriormente, submetidas a análise de conteúdo, que Bardin (2009, p.40) define como "um conjunto de técnicas de análise das comunicações, que utiliza procedimentos sistemáticos e objetivos de descrição do conteúdo das mensagens"

Concluída a leitura integral das entrevistas, numa segunda fase, procedemos a uma leitura mais aprofundada, um constante viajar por cada um dos discursos, que nos abriu o caminho para a análise em duas dimensões: perceções sobre sucesso / insucesso, e fatores que contribuem para o sucesso. Nesta comunicação, apresentamos apenas os resultados da segunda dimensão, com as seguintes categorias: estudo/aprendizagem; avaliação e supervisão parental.

Para a sua categorização, construímos diversos quadros para simplificar o material recolhido, organizando, de forma a possibilitar a análise do corpus e a passagem da descrição à interpretação através da inferência.

$\mathrm{Na}$ tabela 2, que a seguir se apresenta, explicitamos a dimensão, as categorias de análise, bem como as subcategorías para a leitura da realidade. 
Tabela 2.

Fatores que contribuem para o sucesso

\begin{tabular}{|c|c|c|}
\hline Dimensão & Categorias & Subcategorias \\
\hline \multirow{3}{*}{$\begin{array}{l}\text { Fatores } \\
\text { de } \\
\text { sucesso }\end{array}$} & $\begin{array}{l}\text { 1.Estudo/ } \\
\text { aprendizagem }\end{array}$ & $\begin{array}{l}\text { 1.1.Perspetivas (in)sucesso } \\
1.2 \text { O estudo e o sucesso } \\
1.3 \text { Valorização do estudo } \\
\text { para o futuro }\end{array}$ \\
\hline & 2.Avaliação & $\begin{array}{l}\text { 2.1.Avaliação/ } \\
\text { conhecimentos } \\
\text { 2.2.Avaliação/ } \\
\text { comportamentos } \\
\text { 2.3. Avaliação no todo }\end{array}$ \\
\hline & $\begin{array}{l}\text { 3.Supervisão } \\
\text { parental }\end{array}$ & $\begin{array}{l}\text { 3.1.Perspetivas sobre a } \\
\text { escola } \\
\text { 3.2.Acompanhamento e } \\
\text { sucesso } \\
\text { 3.3- curriculo }\end{array}$ \\
\hline
\end{tabular}

\section{Apresentação e análise dos resultados}

Apresentamos os dados recolhidos através das entrevistas, de forma estruturada para cada uma das categorias e subcategorías em análise, recorrendo a unidades de registo.

Em relação à categoria Aprendizagem (tabela 2), identificámos três subcategorías, a partir do discurso dos participantes: "perspectivas sobre o (in)sucesso", "estudo e sucesso " e "valorização do estudo para o futuro".

De um modo geral, para a maioria dos encarregados de educação, ter sucesso é "passar de ano" embora, outras definições sejam de realçar: sucesso é "o futuro do aluno" (AE2), é "um passo à frente" (AE1), "quero é que tenha sucesso na escola e no dia a dia" (AE8), o sucesso é aprender e alcançar os objetivos "há muito interesse do meu educando" e acrescenta, "tem muito prazer em chegar a casa e dar-me boas notícias do seu sucesso" (AE4). O sucesso é também o reflexo do trabalho efetuado com os seus educandos, tal como fica demonstrado na seguinte afirmação: "considero que o trabalho que os pais estão a fazer dá frutos” (AE4).

Quanto ao insucesso, os entrevistados remetem para os processos de inadaptação à escola e para a dificuldade de os alunos construírem um sentido para o trabalho escolar até porque, como alguns admitem, os seus filhos não gostam de estudar e "será um passo atrás que pode comprometer o futuro" (AE1, AE2);"“eu não queria que ele não passasse, mas ele não gosta da escola, está aqui porque é obrigado" (AE3; AE7); "não assumir o compromisso com o estudo (baldar-se) (AE8);"não conseguir atingir os objetivos de alguma forma (AE5).

$\mathrm{O}$ aluno «fracassado» não progrediu praticamente nada, quer no âmbito dos seus conhecimentos escolares, quer ao nível pessoal e social (Marchesi \& Pérez,2003

Para os EE entrevistados, independentemente dos seus educandos terem, ou não, sucesso, ter sucesso escolar significa ter aproveitamento escolar, sendo a classificação a sua grande preocupação, pois ela é determinante no percurso escolar, uma vez que decide sobre o seu progresso na escolaridade. Contudo, alguns EE referem que os educandos têm expectativas elevadas quanto ao estudo, mas também fazem depender o seu sucesso do gosto pela disciplina "Gosta muito de estudar"
(AE4) e "tal como todas as coisas, há matérias que gosta mais do que outras " (AE8), do interesse e do estudo "aquilo que aprende absorve e percebe que o enriquece e por vezes vai aprofundar mais"(AE4).

Mas nem todos gostam do estudo e, por vezes, perdemse, pois as tecnologias são mais apelativas para os seus interesses "pega-se muito ao computador, ao telemóvel, as tecnologias são o ponto fulcral, tem falta de estudo, sem dúvida nenhuma" (AE1).

O estudo e o sucesso na perspetiva dos EE está relacionado "o interesse nas aulas, estar atento e estudar "(AE6), "aplicar-se e esforça-se muito" (AE5). Tirar dúvidas nas aulas, nas aulas de apoio, com os colegas, ou mesmo com os pais é, também, fundamental para compreender os conteúdos "esclarece as dúvidas com o professor se não for nas aulas, nos apoios" (AE1);

"com alguns professores é capaz, com outros tem vergonha" (AE8; AE5); "ele é tímido com certeza não expõe as dúvidas" (AE2).

Relativamente à importância do estudo, os entrevistados consideraram-no muito importante para ter sucesso na escola. Apesar disso, apenas três EE referem que os seus educandos gostam de estudar: gosta muito de estudar, tem tempo para tudo o que os jovens gostam de fazer" (AE4); "eu tinha que lhe dizer, já chega" (AE5); "gosta de estudar, ao fim de semana leva a mochila para a avó" (AE6). Três afirmam que os seus educandos não gostam de estudar "tenho quase a certeza que ele não gosta de estudar AE1); "não gosta de estudar, não estuda quando está comigo" (AE3; AE7). Dois EE dizem que "não é das coisas que ele mais gosta. Gosta mais das tecnologías e fica todo contente quando tem feriados" (AE2; AE8).

Quando questionados sobre a valorização do estudo para o futuro, todos consideram que é importante o estudo "para um dia mais tarde terem um bom futuro" (AE8); "é inquestionável" (AE4); "o futuro depende do estudo" (AE2).

$\mathrm{O}$ estudo funciona, assim, como um auxílio à aprendizagem para ter boa classificação, para ter aproveitamento, para obter bom feedback do professor, em síntese, para ter sucesso na escola e na vida.

Ora, uma vez que "ensinar implica, sempre, avaliar" (Boggino, 2009, p. 80), os professores devem preocuparse com o feedback que dão aos alunos, pois deve conter uma mensagem clara, objetiva e focada na tarefa (Hattie \& Timperley, 2007) no sentido de promover o interesse por melhorar as suas aprendizagens, o seu desempenho e o sucesso escolar. $O$ feedback contribui para elevar a motivação e a autoestima.

No que respeita à avaliação, os EE entrevistados manifestam sentimentos de dualidade: a avaliação serve para aprenderem e serve para serem punidos. Consideram que os professores avaliam tudo: "acho que acabam por $\mathrm{f}$ avaliar o conjunto" (AE5), valorizando todas as dimensões do seu trabalho, ou seja, a avaliação é "para avaliar os conhecimento (AE5), o comportamento, " a atenção nas aulas" (AE1) a concentração, a capacidade de trabalho, a participação, o empenho, a assiduidade, a realização dos trabalhos de casa, a organização do caderno diário e a apresentação dos materiais necessários, ou seja, "para identificar [...] o aluno com 
as suas capacidades" (AE8; AE4). Registamos algunas opiniões que revelam uma postura de desagrado relativamente aos trabalhos de casa, pois representam uma sobrecarga e tem muito peso na avaliação "se eles se aplicarem na escola, já estão lá muitas horas, podiam trazer tudo sabido e às vezes há muito trabalho de casa e se o não fizerem podem ficar penalizados" (AE6; AE8), e acrescentam "mas às vezes, para além dos testes é: um trabalho de grupo; um trabalho individual; uma apresentação; uma oralidade. Alguns EE compreendem que é para benéficio para os seus educandos, "porque se não conseguirem pelos testes vão ter outro material para avaliação “(AE6), mas é exagero. Ora vejamos, “6 ou 7 professores a pedir trabalhos acaba por ser uma sobrecarga muito grande e não sei se vai beneficiar ou não" (AE6). Por outro lado, todos os entrevistados consideram que aquilo que os professores mais valorizam são os testes, pois na opinião de uma EE o que continua a ter mais peso é "os saberes, a parte científica (...) as atitudes são importantíssimas, comportamento, assiduidade, porque não temos bons profissionais só com bom comportamento, é preciso mais. Acho que os saberes devem ter um peso mais significativo" (AE4). No entanto, opinião contrária tem outro EE "os testes são o que tem a maior percentagem". Os testes surgem, assim, como um instrumento de avaliação privilegiado, constatação que confirma a de Barreira e Pinto (2006, p. 59) para os quais "embora os estudos mostrem que os professores utilizam instrumentos diversificados, o que é certo é que os instrumentos com maior peso na avaliação continuam a ser os testes."

Por último, no que concerne a categoría supervisão parental, elegemos a subcategoría perspetivas sobre a escola. Os EE tem uma perspetiva positiva acerca dos diferentes espaços desta escola; "tem boas condições" (AE6). "acho que está muito arranjada para os alunos muito espaço para os alunos estarem" (AE4); "eles tem muito onde ocupar o tempo" (AE1). Em termos de corpo docente referem que" os professores estão aquí para ensinar" (AE3); "apoiam bem os alunos" (AE1); "os apoios a Português, Inglês e Matemática são bons" (AE7); "não podemos esquecer que isto é uma escola pública, os recursos não são inesgotáveis" (AE4).

Nesta subcategoría, destacamos algumas perspetivas sobre envolvimento parental e sucesso escolar. Quando confrontados, os nossos entrevistados EE sobre se o êxito do seu educando estará relacionado com o apoio familiar que lhe é proporcionado, todos unanimemente referem que "o ambiente familiar é muito importante". Mencionam que apoiam o seu educando nas tarefas escolares e surgem aquí três perspetivas diferentes. A primeira valorizando o trabalho do EE "significa que estamos a fazer um bom trabalho" (AE4).; A segunda dando alguma autonomía e responsabilidade no cumprimento das tarefas "damos-lhe alguma autonomia, quando vemos que não está cumprir voltamos logo a andar em cima dele" (AE8). Ppor último, um controlo severo "estou sempre em cima do acontecimento". (AE3).

No que concerne o currículo, os entrevistados referem que é adequado e "não difere muito do do nosso tempo e as disciplinas são quase as mesmas" (AE5). São de opinião que é muito extenso vai demasiado ao pormenor e, por vezes, é repetitivo" (AE4). Apenas um dos entrevistados referiu que o currículo "está sempre a alterar" (AE2). Quanto ao plano curricular, os EE dos alunos com retenções dizem que de algumas disciplinas os seus educandos gostam menos "ele diz-me a Matematica e a Fisica Quimica já põe de parte porque não consegue "(AE1).

Quer os EE dos alunos com sucesso, quer dos que revelam pouco sucesso destacam, neste ponto, a importância não só da ação do professor como do currículo, sobretudo em termos de conteúdos programáticos que, em algumas situações, são motivo de desadequação aos interesses e capacidades dos alunos que os consideram desinteressantes e difíceis.

A este propósito, Charlot (2009, p. 93) salienta que aprender requer uma atividade intelectual, mas "só se engaja numa atividade quem lhe confere um sentido".

\section{Conclusão}

Os resultados revelam algumas convergências e, simultaneamente, bastantes divergências entre os dois grupos de alunos. Todos os EE concordam que o gosto por cada disciplina varia de acordo com os conteúdos e com a relação que estabelecem com o professor. Todos sentem que, independetemente de gostar ou não do profesor, os alunos são apoiados pelos professores para ter bons resultados, através da realização de atividades diversificadas na sala de aula, dos apoios a todas as disciplinas, dos trabalhos de casa e das fichas de avaliação.

Reconhecem que os professores identificam as dificuldades dos seus educandos de modo a ajudá-los a ultrapassá-las, mas consideram que as estratégias de abordagem dos conteúdos não os motivam muito. Consideram o estudo importante para o futuro, mas quando os seus educandos não gostam de estudar, só frequentam a escola por que são obrigados e consideram que a avaliação é um processo de punição, mas é necessário para o sucesso futuro.

Para além das disfunções ao nível da motivação e do autoconceito, de acordó com alguns EE, muitos alunos revelam graves desadequações quanto aos métodos de estudo que utilizam, quanto aos objetivos a alcançar ou quanto aos recursos que são mobilizados. Trata-se de aspetos sobre os quais a escola deveria intervir o mais prontamente possível, encontrando uma articulação eficaz com os $\mathrm{EE}$, na medida em que o insucesso persistente tem efeitos negativos no desenvolvimento pessoal do aluno e no seu rendimento escolar posterior.

\section{Referências}

Alves, M.P. (2004). Currículo e Avaliação - Uma perspectiva integrada. Porto: Porto Editora.

Azevedo, J. (2014). Como se tece o (in)sucesso escolar: o papel crucial dos professores. In Matias, P., et al. (orgs.). Melhorar a escola - sucesso escolar, disciplina, motivação, direção das escolas e politicas educativas. Universidade Católica Porto. Porto: Coleção e-book 
Bardin, L. (2009). Análise de Conteúdo. Lisboa: Edições 70

Barreira, C. \& Pinto, J. (2006). A investigação em Portugal sobre avaliação das aprendizagens dos alunos (1990-2005). http://www.educ.fc.ul.pt/docentes/msantos/spce.pdf , consultado a 10 de novembro de 2009.

Boggino, N. (2009). A avaliação como estratégia de ensino. Avaliar processos e resultados. Sísifo. Revista de Ciências da Educação, 09, 79-86. Disponível em http://sisifo.fpce.ul.pt.

Charlot, B., (2009). A escola e o trabalho dos alunos. Sísifo. Revista de Ciências da Educação, 10, 89-96. Disponivel em http://sisifo.fpce.ul.pt

Crahay, M. (1996). Podemos Lutar Contra o Insucesso Escolar? (Trad. por Brito, I.) Lisboa: Instituto Piaget.

Coutinho, C. (2011). Metodologia de Investigação em Ciências Sociais e Humanas. Teoria e Prática. Coimbra: Edições Almedina

Fernandes, Domingos (2006). Para uma teoria da avaliação formativa. Revista Portuguesa de Educação, 19 (2), pp. 21-50, CIEd - Universidade do Minho. Acedido a 3 de Junho de 2013 em www.scielo.oces.mctes.pt/pdf/rpe/v19n2/v19n2a03.pd $\mathrm{f}$

Formosinho, João, (1991), "A Igualdade em Educação" in A Construção Social da Educação Escolar" pp. 169186.Col. Biblioteca Básica de Educação e Ensino, Edições ASA / Clube do Professor, Rio Tinto.

Formosinho, J. \& Machado.J,. (2012). Autonomia da escola, organização pedagógica e equipas educativas. I n Fialho. I,. \& Verdasca. J,.(org). Turma Mais $e$ Sucesso Escolar fragmentos de um percurso. Centro de Investigação em Educação e Psicologia da Universidade de Évora. ISBN: 978-989-8339-13-3

Acedido a 3 de Junho de 2015 emhttp://www.turmamais.uevora.pt/docs/ciep/L2.pdf

Marchesi, A. \& Pérez, E. M. (2003). La compreensión del fracaso escolar. In A. Marchesi \& C. H. Gil (coords), El fracaso escolar. Una perspetiva internacional. Madrid: Alianza Editorial, pp. 23-50.

Mendonça, A. (2009). O insucesso escolar: Políticas Educ ativas e Práticas Sociais. Um estudo de caso sobre o Arquipélago da Madeira. Mangualde: Edições Pedagogo

Roldão, M. C. (1999). Gestão Curricular: Fundamentos e Práticas. Lisboa: M.E./D.E.B.

Roldão, M. C. (2013). Desenvolvimento do curriculo e a melhoria de procesos e de resultados in Machado J., \& Alves, M., (org.). Melhorar a escola.Sucesso escolar,disciplina,motivação, direção de escolas e políticas educativas. Faculdade de Educação e Psicologia Centro de Estudos em Desenvolvimento Humano (CEDH) \& Serviço de Apoio à Melhoria das Escolas (SAME) Universidade Católica Portuguesa. Porto, 2013, Acedido a 3 de Junho de 2016 em http://repositorio.ucp.pt/bitstream/10400.14/14705/1/ Desenvolvimento $\% 20$ do\%20curr\%C3\%ADculo\%20e $\% 20$ melhoria $\% 20 \mathrm{de} \% 20$ processos $\% 20 \mathrm{e} \% 20$ resultado s.PDF
Santos G. (2003). Tornar visível o quotidiano. Teoria e prática de avaliação qualitativa das escolas. Porto: Asa Santos, T. \& Alves, P. (2016) Avaliação como controle do estudo: perspetiva dos alunos. In Veiga, F. (Coord.) Atas do II Congresso Internacional Envolvimento dos Alunos na Escola: Perspetivas da Psicologia e Educação Motivação para o Desempenho Académico. Lisboa: Instituto de Educação da Universidade de Lisboa, 2016 ISBN: 978-989-8753-35-9.

Sil, V. (2004). Alunos em situação de insucesso escolar: Percepções, estratégias e opiniões dos professores estudo exploratório. Lisboa: Instituto Piaget

Artmed.

Simão, A., (2008). Reforçar o valor regulador formativo e formador da avaliação das aprendizagens. In Alves, M.P. \& Machado, E. A. Avaliação com sentido (s). Contributos e questionamentos. Santo Tirso: De Facto Editores

\section{Agradecimentos}

Este trabalho foi financiado por Fundos Nacionais através da FCT (Fundação para a Ciência e a Tecnologia) e cofinanciado pelo Fundo Europeu de Desenvolvimento Regional (FEDER) através do COMPETE 2020 Programa Operacional Competitividade e Internacionalização (POCI) no âmbito do CIEC (Centro de Investigação em Estudos da Criança da Universidade do Minho) com a referência POCI-01-0145-FEDER007562 . 